\title{
Novel Polymeric Prodrugs of Valproic Acid as Anti- Epilepsy Drugs: Synthesis, Characterization and In-vitro Evaluation
}

\author{
Seyyedeh Nazanin Amiryaghoubi and Mirzaagha Babazadeh* \\ Department of Chemistry, Tabriz Branch, Islamic Azad University, Tabriz, Iran
}

*For correspondence: Email: babazadeh@iaut.ac.ir; Tel: 00984133396024

Received: 27 April 2015

Revised accepted: 15 June 2015

\begin{abstract}
Purpose: To synthesize and evaluate, in-vitro, novel polymeric prodrugs of valproic acid (VPA) for antiepileptic activity.

Methods: Homopolymer of 4-chloromethyl styrene (CMS) and its copolymers with various acrylic-type monomers such as 2-hydroxyethyl methacrylate and methyl methacrylate were prepared by free radical polymerization method. VPA was then covalently linked to the obtained polymers by treating CMS polymers with sodium valproate. All the compounds were characterized by Fourier transform infrared (FT-IR), nuclear magnetic resonance $\left({ }^{1} \mathrm{H}\right.$ and $\left.{ }^{13} \mathrm{C}-\mathrm{NMR}\right)$, elemental analyses, and gel permeation chromatography (GPC). The release of VPA from polymeric prodrugs was studied using cellophane membrane dialysis bags containing aqueous buffer solutions ( $p H 1,7$ and 10) at $37^{\circ} \mathrm{C}$. The quantity of released drug was detected by ultraviolet (UV) spectroscopy.

Results: ${ }^{1} \mathrm{H}$-NMR and elemental analyses data for calculating mole composition of CMS polymers were relatively in good agreement. FT-IR and NMR data for the polymeric prodrugs showed attachment of drug substituents to phenyl rings of CMS units via methylene spacer. The drug-release profiles indicated that selective hydrolysis of ester bond between the drug and the polymer backbone is strongly dependent on polymer hydrophilicity and the $\mathrm{pH}$ of the hydrolysis solution.

Conclusion: The synthesized VPA polymeric prodrugs may be cost-effective compounds for release of VPA in vivo when formulated as controlled release systems.
\end{abstract}

Keywords: 4-Chloromethyl styrene, Valproic acid, Polymeric prodrugs, Controlled release, Hydrolysis

Tropical Journal of Pharmaceutical Research is indexed by Science Citation Index (SciSearch), Scopus, International Pharmaceutical Abstract, Chemical Abstracts, Embase, Index Copernicus, EBSCO, African Index Medicus, JournalSeek, Journal Citation Reports/Science Edition, Directory of Open Access Journals (DOAJ), African Journal Online, Bioline International, Open-J-Gate and Pharmacy Abstracts

\section{INTRODUCTION}

Polymeric prodrugs or polymer-drug conjugations are novel technique for drug delivery systems. In these systems, macromolecular chains act as carriers for drugs in a physically bound state or by true chemical linkages as side groups. These latter systems, in which drugs are delivered by chemically or biologically induced cleavage of the covalent bonds, increase water solubility, stability, and therapeutic efficiency of drugs whit reducing the required doses, side effects, and toxicity of drugs by controlling the rate, duration, and site of release [1-3].

Valproic acid (VPA), so called (2-propylpentanoic acid), is a branched short-chain fatty acid derived from naturally occurring valeric acid. VPA is used in the treatment of epilepsy and seizures but also migraine, bipolar, mood, anxiety and psychiatric disorders [4-7]. VPA has been used in combination with sodium valproate. These 
formulations show smaller differences in the pharmacokinetics and accessibility in market [8]. VPA single or in combination with sodium valproate is available in different dosage forms; capsule, tablet, enteric-coated tablet, sprinkle, liquid, intravenous, suppository and controlledrelease formulations [9]. Valproate is believed to affect the function of the neurotransmitter $y$ aminobutyric acid (GABA) in the human brain. VPA inhibits GABA transaminase by binding to it and thus enhances the neurotransmission of GABA in brain $[10,11]$. VPA also blocks the voltage-gated sodium channels and T-type calcium channels [12]. These mechanisms make VPA a broad-spectrum anticonvulsant drug.

4-Chloromethyl styrene (CMS) is a dual functional monomer that can polymerize or copolymerize before or after functional reactions with the benzyl chloride group. Polychloromethyl styrene (PCMS) and related copolymers are able to react with various nucleophilic reagents at fairly high yields $[13,14]$. Functionalized PCMS and its copolymers have been widely used in different processes as photo-sensitizers [15], solar energy storage [16], photo-resists [17], nonlinear optics [18], cholesterol trapping of human serum [19], and prodrugs in biomedical applications [20].

In previous works, we reported the synthesis and in-vitro evaluation of some acrylic-type polymeric prodrugs of non-steroidal anti-inflammatory drugs (NSAIDs) such as ibuprofen, naproxen, ketoprofen, diclofenac, and 5-aminosalicylic acid [21-28].

In this research work, the synthesis and comparative study of the hydrolytic behavior of polymeric drugs based on CMS bearing VPA is reported. CMS was homopolymerized and copolymerized with 2-hydroxyethyl methacrylate (HEMA) and methyl methacrylate (MMA) by free radical polymerization method. VPA was then linked to the resulted polymers by nucleophilic substitution reaction. The in-vitro hydrolysis behavior of the polymeric prodrugs was studied in physiological conditions at $37^{\circ} \mathrm{C}$. Hydrophilic properties of polymeric prodrugs and $\mathrm{pH}$ values of hydrolysis media are affected on the basis of results obtained in-vitro evaluation.

\section{EXPERIMENTAL}

\section{Materials}

Sodium valproate was purchased from Sigma. HEMA and MMA were obtained from Merck and purified by distillation under reduced pressure to remove inhibitors. CMS was purchase from Acros Organics and used as received. Azobisisobutyronitrile (AIBN) was obtained from Fluka and recrystallized twice from methanol. All other chemicals were reagent grade or purer.

\section{Instrumental measurements}

FT - IR spectra were recorded on a Shimadzu 4300 spectrophotometer. 1H - NMR spectra were recorded on Bruker $400 \mathrm{MHz}$ spectrometer in $\mathrm{CDCl} 3$ solution. The amount of released VPA was determined by a 2100 Shimadzu UV spectrophotometer at the adsorption maximum of the free VPA in aqueous buffered solutions (213 $\mathrm{nm}$ ) using a $1-\mathrm{cm}$ quartz cell. The values of number - average molecular weight $(\mathrm{Mn})$, weight average molecular weight $(\mathrm{Mw})$ and the polydispersity index of polymers were determined with a Maxima 820 gel permeation chromatography (GPC) instrument. Well characterized polyethylene oxide was used in the calibration within the range of $\mathrm{Mw}$ between "2600- 885000". Elemental analyses were carried out with a Heareus CHN-ORAPID instrument.

\section{Synthesis of PCMS (P1)}

In a quickfit Pyrex polymerization tube, $0.032 \mathrm{~g}$ $(0.2 \mathrm{mmol})$ of AIBN and $3.0 \mathrm{~g}(20 \mathrm{mmol})$ of CMS were dissolved in $10 \mathrm{ml}$ of toluene, and the solution flushed gently with argon for about 20 $\min$. Then the solution was shaken vigorously in a thermostatic water bath at $70 \pm 1{ }^{\circ} \mathrm{C}$ under argon for $12 \mathrm{~h}$. After this time, the resulted yellowish viscous solution was poured into 120 $\mathrm{ml}$ of cooled methanol as a non-solvent. The precipitated PCMS was collected and dissolved in $15 \mathrm{ml}$ of toluene and poured into $100 \mathrm{ml}$ of cooled methanol. The obtained white precipitate was washed with methanol and dried in vacuum at room temperature to give $2.6 \mathrm{~g}$ of P1. FT-IR (KBr): 3030 (aromatic $\mathrm{C}-\mathrm{H}$ ), 2910, 2860 (aliphatic $\mathrm{C}-\mathrm{H}), 1590,1480 \mathrm{~cm}^{-1}$ (aromatic $\mathrm{C}=\mathrm{C}$ ). ${ }^{1} \mathrm{H}-\mathrm{NMR}$ $\left(\mathrm{CDCl}_{3}\right): \delta=1.4\left(2 \mathrm{H}, \mathrm{CH}_{2}-\mathrm{CH}\right), 1.9\left(1 \mathrm{H}, \mathrm{CH}_{2}-\right.$ $\mathrm{CH}), 4.5\left(2 \mathrm{H}, \mathrm{CH}_{2}-\mathrm{Cl}\right), 6.3-7.2(4 \mathrm{H}, \mathrm{Ar}-\mathrm{H}) .{ }^{13} \mathrm{C}-$ NMR $\left(\mathrm{CDCl}_{3}\right): \delta=40\left(1 \mathrm{C}, \mathrm{CH}_{2}-\mathrm{CH}\right), 41(1 \mathrm{C}$, $\left.\mathrm{CH}_{2}-\mathrm{CH}\right), 46.2\left(1 \mathrm{C}, \mathrm{CH}_{2}-\mathrm{Cl}\right), 125,128.9,135$ and 145.5 (aromatic carbons).

\section{Copolymerization of CMS with acrylic-type monomers: general procedure}

Poly(CMS-co-HEMA) (P2) and poly(CMS-coMMA) (P3) were synthesized as follows.

A mixture of $0.5 \mathrm{~g}(3.2 \mathrm{mmol})$ of $\mathrm{CMS}, 0.02 \mathrm{~g}$ 
$(0.13 \mathrm{mmol})$ of AIBN and $1.25 \mathrm{~g}(9.6 \mathrm{mmol})$ of HEMA or $0.96 \mathrm{~g}(9.6 \mathrm{mmol})$ of MMA was dissolved in $10 \mathrm{ml}$ of dried DMF in a Pyrex glass ampoule. Then the ampoule was degassed, sealed under vacuum and maintained at $70 \pm 1$ ${ }^{\circ} \mathrm{C}$ in a water bath and shaken for about $30 \mathrm{~h}$. Then the viscous solution of ampoule was poured into $150 \mathrm{ml}$ of cooled ethanol. The precipitate was collected and washed with nonsolvent for several times and dried under vacuum at room temperature to give $1.3 \mathrm{~g}$ of $\mathbf{P 2}$ or $1.1 \mathrm{~g}$ of P3.

\section{Synthesis of polymeric prodrugs containing VPA}

In a $100 \mathrm{ml}$ two-necked flask equipped with a dropping funnel and a reflux condenser, $1 \mathrm{~g}$ of $\mathbf{P} 1$ or $\mathbf{P} \mathbf{2}$ or $\mathbf{P} \mathbf{3}$ was dissolved in $10 \mathrm{ml}$ of DMF. A gas-inlet is attached to the top of the dropping funnel and the system is maintained under a slight pressure of argon. A solution of $2 \mathrm{~g}$ (12 $\mathrm{mmol})$ of sodium valproate in DMF $(30 \mathrm{ml})$ was added dropwise from dropping funnel with stirring to solution of polymers into flask at room temperature. The reaction mixture was heated at $80{ }^{\circ} \mathrm{C}$ for about $3 \mathrm{~h}$, and stirred for $12 \mathrm{~h}$ at room temperature. Then, the solution was poured into an excess cooled methanol and the precipitate filtered and washed with water for several times to removing $\mathrm{NaCl}$ and unreacted drug. The obtained polymers containing VPA substituents (P1-VPA, P2-VPA or P3-VPA) was collected and dried under vacuum in high yield (73-85 \%).

\section{Method of hydrolysis}

Each of dried polymer - drug conjugates (200 $\mathrm{mg}$ ) was poured into $5 \mathrm{ml}$ of an aqueous buffered solution $\left(\mathrm{pH} 1,7\right.$ and 10) at $37{ }^{\circ} \mathrm{C}$ and the mixture was conducted into a cellophane membrane dialysis bag. The bag was closed and transferred into a flask containing $25 \mathrm{ml}$ of same buffer solution maintained at $37^{\circ} \mathrm{C}$. The external solution was continuously stirred and a $3-\mathrm{ml}$ sample was removed at selected intervals and 3 $\mathrm{ml}$ of buffer was replaced. The quantity of released drug was analyzed by means of an UV spectrophotometer and determined from the calibration curve obtained previously under the same conditions.

\section{Characterization of hydrolysis products}

The polymer-drug adduct $(20 \mathrm{mg})$ was dispersed into $20 \mathrm{ml}$ of buffered solution $(\mathrm{pH} 10)$ and maintained at $37^{\circ} \mathrm{C}$. After $24 \mathrm{~h}$, the hydrolysis solution was sampled, neutralized with $1 \mathrm{~N} \mathrm{HCl}$ and the solvent was removed in vacuum. The resulting crude product was treated with $10 \mathrm{ml}$ of acetone and heated. The suspension was then filtered and the acetone solution was evaporated under reduced pressure. The residue as a clear colorless liquid with boiling point $220^{\circ} \mathrm{C}$ showed that the hydrolysis product is VPA.

\section{RESULTS}

\section{Characteristics of polymers P1-P3}

The CMS was easily hompolymerized and copolymerized with HEMA and MMA by free radical polymerization technique at $70 \pm 1{ }^{\circ} \mathrm{C}$ using AIBN to obtain amorphous P1-P3. The resulted polymers were soluble in DMSO and DMF, but insoluble in alcohols and water. The prepared polymers were characterized by FT-IR, ${ }^{1} \mathrm{H}-\mathrm{NMR}$ and ${ }^{13} \mathrm{C}-\mathrm{NMR}$ spectroscopy. The FT-IR spectra of polymers P1-P3 showed a peak at $3035 \mathrm{~cm}^{-1}$ due to $\mathrm{C}-\mathrm{H}$ stretching of the aromatic ring. The peaks at 2996 and $2950 \mathrm{~cm}^{-1}$ were attributed to the asymmetrical and symmetrical $\mathrm{C}-\mathrm{H}$ stretching of methylene and methyl groups. The ester carbonyl stretching was observed at $1735 \mathrm{~cm}^{-1}$. The ring stretching vibrations of the aromatic nuclei were observed at 1600 and 1485 $\mathrm{cm}^{-1}$. The hydroxyl stretching vibration of $\mathbf{P 2}$ was observed at $3400 \mathrm{~cm}^{-1}$. The asymmetrical and symmetrical bending vibrations of methyl groups are seen at 1453 and $1380 \mathrm{~cm}^{-1}$, respectively. The peaks at 1273 and $1160 \mathrm{~cm}^{-1}$ were due to C$\mathrm{O}$ stretching. The elemental analyses data for the synthesized $\mathbf{P 1 - P 3}$ are presented in Table 1.

In the ${ }^{1} \mathrm{H}$-NMR spectra of P1-P3, two methylene protons of benzyl chloride appeared at $4.6 \mathrm{ppm}$. The proton signals of the aryl group were seen Table 1: Molecular weights, calculation of integrated peak area of protons, mole compositions, and elemental analysis of P1-P3

\begin{tabular}{lcccccccccc}
\hline Sample & $\begin{array}{c}\mathbf{M}_{\mathbf{n}} \\
\left(\times \mathbf{1 0}^{-3}\right)\end{array}$ & $\begin{array}{c}\mathbf{M}_{\mathbf{W}} \\
\left(\times \mathbf{1 0}^{-3}\right)\end{array}$ & $\mathbf{M}_{\mathbf{w}} / \mathbf{M}_{\mathbf{n}}$ & $\mathbf{I}_{\text {Ar }}{ }^{\mathbf{a}}$ & $\mathbf{I}_{\text {Ali }}{ }^{\mathbf{b}}$ & $\mathbf{B}$ & $\begin{array}{c}\mathbf{C M S} \\
(\mathbf{\%})\end{array}$ & $\begin{array}{c}\text { Comonomer } \\
(\%)\end{array}$ & $\mathbf{C}(\%)$ & $\begin{array}{c}\mathbf{H} \\
(\%)\end{array}$ \\
\hline P1 & 35.2 & 63.4 & 1.8 & - & - & - & 100 & - & 70.8 & 5.9 \\
P2 & 23.2 & 48.7 & 2.1 & 3.9 & 25.6 & 0.15 & 32 & 68 & 60.9 & 7.0 \\
P3 & 27.5 & 46.7 & 1.7 & 4.1 & 25.1 & 0.16 & 29 & 71 & 63.8 & 7.2 \\
\hline
\end{tabular}

antegrated peak area of aromatic protons in copolymer; ${ }^{b}$ integrated peak area of aliphatic protons in copolymer 


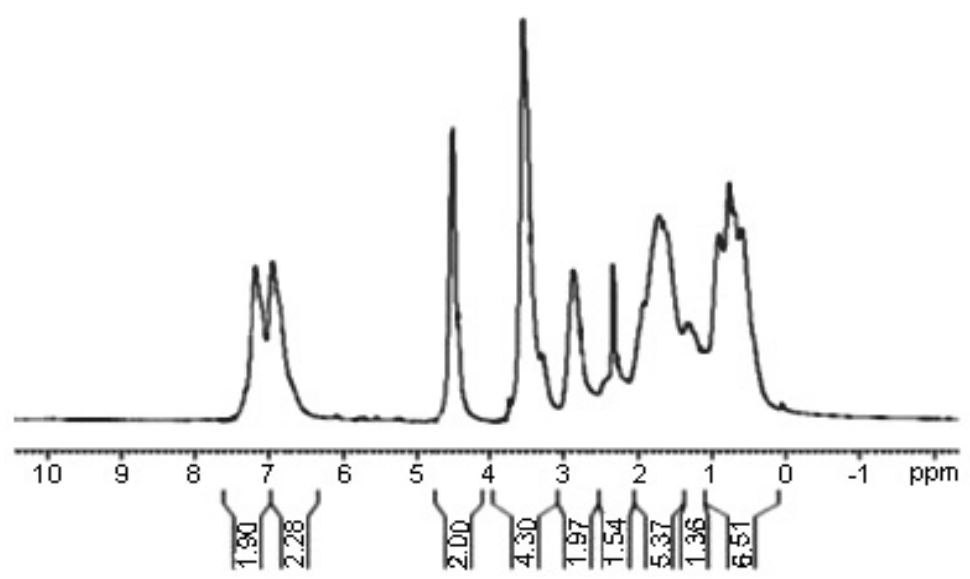

Figure 1: ${ }^{1} \mathrm{H}-\mathrm{NMR}$ spectrum of copolymer $\mathbf{P} 3$ in $\mathrm{CDCl}_{3}$

between 6.7 and $7.2 \mathrm{ppm}$. The resonance signal at $4 \mathrm{ppm}$ was attributed to two methylene protons of $-\mathrm{COOCH}_{2}$ in copolymer $\mathbf{P 2}$, and three methyl protons of $-\mathrm{COOCH}_{3}$ in copolymer $\mathbf{P} \mathbf{3}$ appeared at $3.6 \mathrm{ppm}$. Also, one proton of hydroxyl group of P2 appeared at $5.0 \mathrm{ppm}$. The broad signal at 0.7$2.9 \mathrm{ppm}$ was due to the methylene groups of backbone and other alkyl groups. A typically ${ }^{1} \mathrm{H}$ NMR spectrum of the copolymer P3 is shown in Figure 1.

In the ${ }^{13} \mathrm{C}-\mathrm{NMR}$ spectra of P1-P3, the resonance signal at $176.5 \mathrm{ppm}$ was due to the ester carbonyl carbon in copolymers. The aromatic carbons gave signals at 128.2, 128.7, 135.3 and $145.5 \mathrm{ppm}$. The signal at $46 \mathrm{ppm}$ was attributed to the methylene carbon of benzyl chloride. The methyl and methylene carbons attached to the oxygen of ester appeared at 51.6 and 59.6 ppm, respectively. The backbone carbon signals were observed at $40-45 \mathrm{ppm}$. The signal at $12.5 \mathrm{ppm}$ was due to a-methyl group.

The number and weight-average molecular weights of the synthesized polymers P1-P3 were determined by GPC and are presented in Table 1. The average composition of the copolymer samples was determined from the corresponding ${ }^{1} \mathrm{H}$-NMR spectra and elemental analysis. In the past few decades ${ }^{1} \mathrm{H}$-NMR spectroscopic analysis and elemental analysis have been established as a powerful tool for the determination of copolymer compositions because of its simplicity, rapidity and sensitivity $[29,30]$. The assignment of the resonance peaks in the ${ }^{1} \mathrm{H}$-NMR spectrum leads to the accurate evaluation of the content of each kind of monomeric unit incorporated into the copolymer chains. Thus, the mole fraction of CMS in the copolymer chain was calculated from measuring the integrated peak areas of aromatic protons of the CMS unit and aliphatic protons of the CMS and other monomer units. The following expression is used to determine the composition of copolymer P3. Let $m$ be the mole fraction of CMS and 1-m or $n$ is that of MMA monomer. The CMS contains four aromatic protons and five aliphatic protons and MMA contains eight aliphatic protons:

$B=I_{\text {Ar }} / I_{A l i}=4 m /[5 m+8(1-m)]$

Where $I_{A r}$ is the integrated peak area of aromatic protons and $I_{\text {Ali }}$ is the integrated peak area of aliphatic protons.

On simplification, equation 1 becomes

$m=8 B /(3 B+4)$

Therefore, the mole fraction of CMS in the copolymer P3 was determined from Eq. 2. A similar method was used to calculate of the mole compositions of $\mathbf{P 2}$. Table 1 gives the values of $B$ and the corresponding mole fractions of $\mathrm{CMS}$ and related co-monomer in the copolymers. The results obtained from ${ }^{1} \mathrm{H}-\mathrm{NMR}$ data and elemental analyses were relatively in good agreement.

\section{Synthesis of polymeric prodrugs containing VPA}

Because of the mobility of the benzyl chloride bonds in the resulted polymers P1-P3, nucleophilic substitutions were possible and easy. Therefore, a solution of sodium valproate as a nucleophilic reagent reacted with benzyl chloride bonds in polymers with replacement of the chlorine atoms to give new polymeric 
prodrugs and VPA substituents attached to phenyl rings via methylene spacer. These new polymeric prodrugs P1-VPA, P2-VPA and P3VPA were isolated in the related non-solvent in high yields.

The obtained polymeric prodrugs containing VPA were soluble in the same solvents that copolymers P1-P3 are dissolved. The dissolving time for copolymers containing VPA groups was longer in comparison with copolymers without VPA groups. Since, with incorporating of VPA in polymer structure, the free volume of the polymer decreases. Therefore the solvent entering time between polymer chains is long and mild heat for dissolving is occasionally required.

The replacement of chlorine atom by VPA group is easily followed by NMR technique. The obtained ${ }^{1} \mathrm{H}-\mathrm{NMR}$ spectra for polymeric prodrugs showed that VPA groups replace all the chlorine atoms. With replacement of chlorine atoms by VPA substituents, the peak at $4.6 \mathrm{ppm}$ corresponding to two methylene protons of benzyl chloride disappears and new signals at 0.7-3.0 ppm due to fifteen aliphatic protons of VPA group appear. The other chemical shift assignments for polymeric prodrugs are the same observed chemical shifts for polymers P1P3.

In the ${ }^{13} \mathrm{C}$-NMR spectra of polymeric prodrugs, carbon absorption at $46 \mathrm{ppm}$ corresponding to one methylene carbon of benzyl chloride disappears and a new peak at $65 \mathrm{ppm}$ appears. Also, a new signal at $179 \mathrm{ppm}$ corresponding to new ester carbonyl carbon and four signals at 50 , 34, 21 and $15 \mathrm{ppm}$ corresponding to aliphatic carbons of VPA observes, respectively.

\section{Drug release from polymeric prodrugs}

The in-vitro hydrolysis behavior of polymeric prodrugs was studied in physiological conditions (aqueous phosphate or hydrochloric acid buffers, at $37^{\circ} \mathrm{C}$ ). As the polymers were not soluble in water, they were dispersed in buffer solution and the hydrolysis was performed in a heterogeneous system. The hydrolysis was carried out in cellophane membrane bags permeable to low molecular weight compounds. The released drug passed through the high molecular weight polymers into the external buffer solution and determined by a UV spectrophotometer.

Figures 2 and 3 , show the release of VPA from polymeric prodrugs as a function of time under mild conditions in $\mathrm{HCl}$ buffer $(\mathrm{pH} 1)$ and $\mathrm{KH}_{2} \mathrm{PO}_{4^{-}}$
$\mathrm{Na}_{2} \mathrm{HPO}_{4}$ buffer $(\mathrm{pH} 7$ and 10$)$. The order of hydrolysis is: P2-VPA > P1-VPA > P3-VPA.
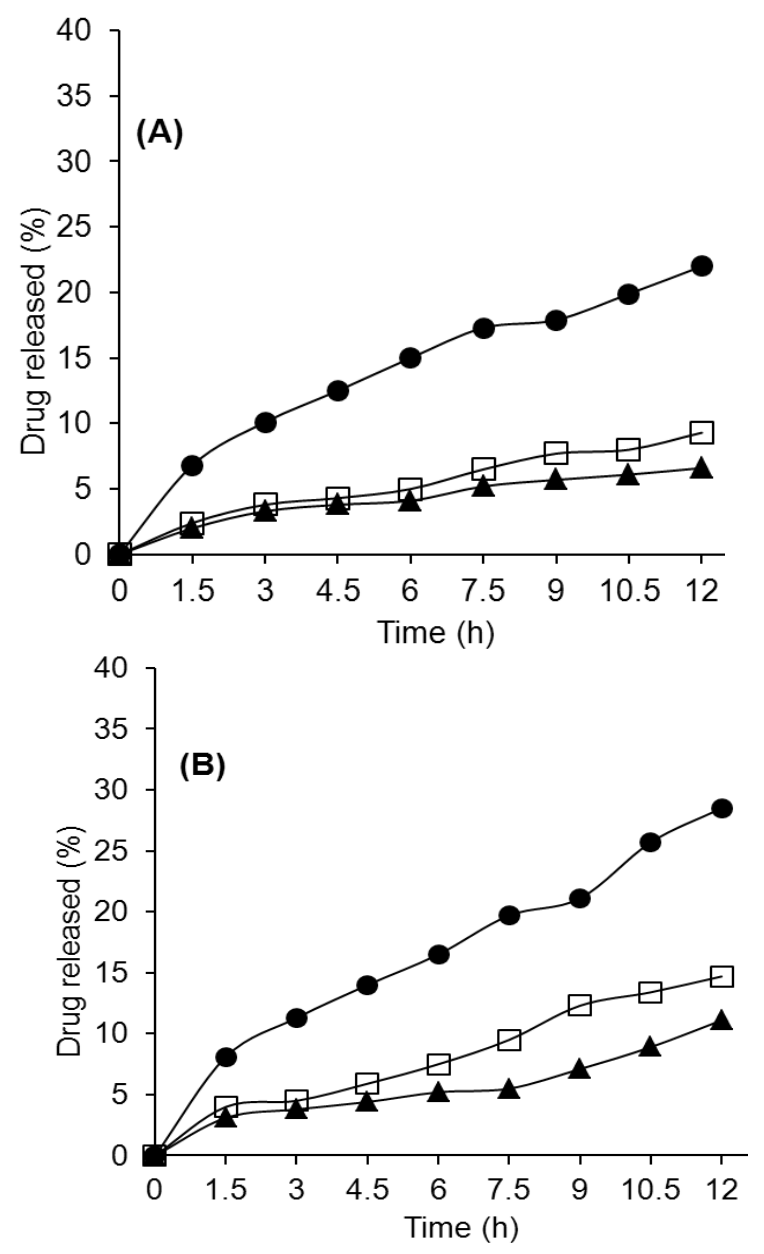

Figure 2: VPA release from polymeric carriers as a function of time in $(A)$ hydrochloric acid buffer $(\mathrm{pH} 1)$ and $(B)$ phosphate buffer $(\mathrm{pH})$ at $37^{\circ} \mathrm{C}$. $\triangle \mathrm{P} 3-\mathrm{VPA}$, $\square$ P1-VPA, and $\bullet$ P2-VPA.

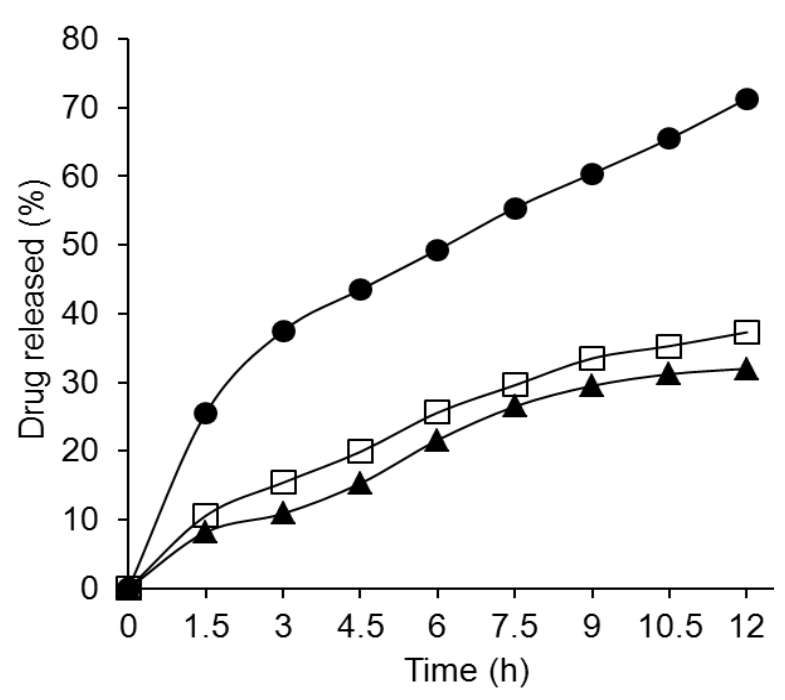

Figure 3: VPA release from polymeric carriers as a function of time in phosphate buffer $(\mathrm{pH} 10)$ at $37^{\circ} \mathrm{C}$. $\triangle P 3-V P A$, P1-VPA, and $\bullet$ P2-VPA 


\section{DISCUSSION}

It has been widely demonstrated that the side chain hydrolysis of drug pendent polymers depends on the strength and chemical nature of the drug polymer chemical bonds, the structure of the polymer and the surrounding condition. The length and hydrophilicity of the spacer unit between the drug and polymer chain can affect the release rate. Two hydrolysable ester bonds were present in the synthesized prodrugs. Detection of the hydrolyzing solution by UV spectrophotometer showed that only the ester bond between drug moiety and methylene group was hydrolyzed during the reaction time. This matter was evidenced from the IR and melting point measurement of the residual compound after hydrolysis, which corresponded to the free drug. The direct ester linkage between the main chain of polymer and methylene group was not undergo hydrolysis under mild conditions. This can be related to the steric hindrance of bulk polymer chains, which decrease the bond mobility.

As shown in Figures 2 and 3, the release rate of VPA from polymeric prodrugs at alkaline medium was higher than the release rate of drug in acidic condition. It seems that polymeric prodrugs have low degree of swelling in acidic medium and the drug is protected against hydrolysis. Also, at acidic media, the carboxyl group of hydrolyzed VPA will be protonated and its aqueous solubility will be lower than in alkali media, where the acid group is deprotonated. Also, the hydrolysis of ester in acidic media is actually an equilibrium reaction, as ester formation is also catalyzed by acid. The degree of hydrolysis increases as the polymer passes from acidic to alkali medium. In alkali $\mathrm{pH}$, the polymers have reached a degree of swelling that makes the labile bonds accessible to hydrolysis.

Different factors such as solubility of polymers and neighbouring effect of side groups can affect the overall rate of hydrolysis. The hydrophilic copolymer containing VPA was hydrolyzed in buffer solutions rather than hydrophobic copolymer. As shown in Figures 2 and 3, P2VPA was rapidly hydrolyzed because of higher hydrophilicity of HEMA units and P3-VPA was slowly hydrolyzed because of hydrophobicity of MMA units in the copolymer structure. The results show that with passing polymeric prodrugs from acidic media to slightly alkaline $\mathrm{pH}$, the labile bonds are better accessible to hydrolysis. Therefore, in alkaline $\mathrm{pH}$ value, the polymers are easily degraded to release of VPA.

\section{CONCLUSION}

A series of novel polymeric prodrugs containing VPA pendent groups has been successfully synthesized as materials for drug delivery systems. Introducing hydrophilic units along the polymer chains improves hydrolytic behaviour. The developed systems would be useful for the development of $\mathrm{pH}$-sensitive polymeric prodrugs for controlled release systems. As the main purpose of polymeric prodrugs is the achievement of controlled drug release. However, in-vivo studies are required to determine their suitability in clinical applications.

\section{REFERENCES}

1. Ratner BD, Hoffmann AS, Schoen FJ, Lemons JE. Biomaterials science: an introduction to materials in medicine. London: Elsevier Academic Press; 2004.

2. Khandare J, Minko T. Polymer-drug conjugates: progress in polymeric prodrugs. Prog Polym Sci 2006; 31: 359397.

3. Hoste K, Winne K, Schacht E. Polymeric prodrugs. Int J Pharm 2004; 277: 119-131.

4. Fariello RG, Varasi $M$, Smith MC. Valproic acid: mechanism of action. In: Levi RH, Mattson $R H$, Meldrum BS, Eds. Antiepileptic drugs. New York: Raven Press; 1995; pp 581-588.

5. Calabresi $P$, Galletti $F$, Rossi $C$, Sarchielli $P$, Cupini LM. Antiepileptic drugs in migraine: from clinical aspects to cellular mechanisms. Trends Pharmacol Sci 2007; 28: 188-195.

6. Chateauvieux S, Morceau F, Dicato M, Diederich $M$. Molecular and therapeutic potential and toxicity of valproic acid. J Biomed Biotechnol 2010: 1-18.

7. Tan J, Cang S, Ma Y, Petrillo RL, Liu D. Novel histone deacetylase inhibitors in clinical trials as anti-cancer agents. J Hematol Oncol 2010; 3(1): 5-13.

8. Phaechamud $T$, Mueannoom $W$, Tuntarawongsa $S$, Chitrattha S. Preparation of coated valproic acid and sodium valproate sustained-release matrix tablets. Indian J Pharm Sci 2010; 72(2): 173-183.

9. Loscher $W$. Valproate: a reappraisal of its pharmacodynamic properties and mechanisms of action. Prog Neurobiol 1999; 58(1): 31-59.

10. Johannessen CU, Johannessen SI. Valproate: past, present, and future. CNS Drug Rev 2003; 9(2): 199216.

11. Johannessen CU. Mechanisms of action of valproate: a commentatory. Neurochem Int 2000; 37(2-3): 103110.

12. Zhang L, Ma N, Liu Q, Ma Y. Genome-wide screening for genes associated with valproic acid sensitivity in fission yeast. PLoS One 2013; 8(7): e68738.

13. Safa KD, Babazadeh M, Namazi H, Mahkam M, Asadi MG. Synthesis and characterization of new polymer systems containing very bulky tris(trimethylsilyl)

Trop J Pharm Res, July 2015; 14(7): 1188 
methyl substituents as side chains. Eur Polym $J$ 2004; 40: 459-466.

14. Babazadeh M. Thermal stability and high glass transition temperature of 4-chloromethyl styrene polymers bearing carbazolyl moieties Polym Degrad Stab 2006; 91: 3245-3251.

15. Nishikubo T, Kondo T, Inomata K. Study of polymeric photosensitizers: synthesis of multifunctional photosensitizers bonded on cross-linked polymer beads and their application for photoisomerization of potassium sorbate. Macromolecules 1989; 22(10): 3827-3833.

16. Taoda H, Hayakawa K, Kawase K, Yamakita $H$. Photochemical conversion and storage of solar energy by azobenzene. J Chem Eng Jpn 1987; 20(3): 265-270.

17. Cheng CM, Egbe MI, Grasshoff JM, Guarrera DJ, Pai $R P$, Warner JC, Synthesis of 1-(vinylbenzyl)thymine, a novel, versatile multi-functional monomer. J Polym Sci Part A Polym Chem 1995; 33(14): 2515-2519.

18. Noel C, Ching KC, Large M, Reyx D, Kajzar F. Synthesis and characterization of polymers containing 4cyanobiphenyl-based side groups for nonlinear optic applications. part 3. poly( p-chloromethyl styrene) derivatives. Macromol Chem Phys 1997; 198(5): 1665-1678.

19. Kihara K, Toda H, Mori M, Hashimoto M, Mizogami S. The bile acid binding and hypocholesterolemic activity of anion-exchange resins bearing the imidazolium salt group. Eur J Med Chem 1988; 23(5): 411-415.

20. Tabrizi MH, Davaran S, Entezami A. Synthesis of diclofenac polymeric prodrugs and their hydrolysis reactivity. Iran Polym J 1996; 5(4): 243-251.

21. Babazadeh $M$, Sheidaei $M$, Abbaspour S, Edjlali $L$. Synthesis, characterization, and in vitro evaluation of new ibuprofen polymeric prodrugs based on 2hydroxypropyl methacrylate. Sci Pharm 2013; 81: 281-296.
22. Babazadeh M. Synthesis and study of controlled release of ibuprofen from the new acrylic type polymers. Int $J$ Pharm 2006; 316: 68-73.

23. Babazadeh M. Design, synthesis and in vitro evaluation of vinyl ether type polymeric prodrugs of ibuprofen, ketoprofen and naproxen. Int J Pharm 2008; 356: 167-173.

24. Babazadeh M, Mosanejhad T. Vinyl ester type polymers containing ibuprofen pendents: synthesis, characterization and evaluation. Iran Polym J 2009; 18: 179-186.

25. Namazi $H$, Babazadeh $M$, Sarabi A, Entezami $A A$. Synthesis and hydrolysis of acrylic type polymers containing nonsteroidal antiinflammatory drugs. $J$ Polym Mater 2001; 18: 301-311.

26. Babazadeh M, Edjlali L, Rashidian L. Application of 2hydroxyethyl methacrylate polymers in controlled release of 5-amino salicylic acid as a colon-specific drug. J Polym Res 2007; 14: 207-213.

27. Babazadeh M. Synthesis, characterization, and in vitro drug-release properties of 2-hydroxyethyl methacrylate copolymers. J Appl Polym Sci 2007; 104: 2403-2409.

28. Babazadeh M. Synthesis and in vitro evaluation of acrylate-based macromolecular prodrugs containing mesalazine for colon-specific drug delivery. Der Pharma Chem 2014; 6(3): 411-419.

29. Chang $\mathrm{CH}$, Sheu YM, Hu WP, Wang LF, Chen JS. Synthesis and properties of copolymers from 2hydroxyethyl methacrylate-linked nonsteroidal antiinflammatory agents with methacrylic acid. J Polym Sci Polym Chem 1998; 36: 1481-1489.

30. Selvamalar CSJ, Krithiga T, Penlidis A, Nanjundan S. Copolymerization of 4-benzyloxycarbonylphenyl methacrylate with glycidyl methacrylate: synthesis, characterization, reactivity ratios and application as adhesives. React Funct Polym 2003; 56: 89-101. 